\title{
Effectiveness of the blended-care lifestyle intervention 'PerfectFit': a cluster randomised trial in employees at risk for cardiovascular diseases
}

Tessa A. Kouwenhoven-Pasmooij ${ }^{1,2,3^{*}}$ D, Suzan J. W. Robroek ${ }^{2}$, Roderik A. Kraaijenhagen ${ }^{4}$, Pieter H. Helmhout ${ }^{5}$, Daan Nieboer ${ }^{2}$, Alex Burdorf ${ }^{2}$ and M. G. Myriam Hunink $k^{1,6,7}$

\begin{abstract}
Background: Web-based lifestyle interventions at the workplace have the potential to promote health and work productivity. However, the sustainability of effects is often small, which could be enhanced by adding face-to-face contacts, so-called 'blended care'. Therefore, this study evaluates the effects of a blended workplace health promotion intervention on health and work outcomes among employees with increased cardiovascular risk.

Methods: In this multicentre cluster-randomised controlled trial (PerfectFit), 491 workers in 18 work units from military, police, and a hospital with increased cardiovascular risk were randomised into two intervention groups. The limited intervention ( $n=213 ; 9$ clusters) consisted of a web-based Health Risk Assessment with advice. In the extensive intervention ( $n=271 ; 8$ clusters), coaching sessions by occupational health physicians using motivational interviewing were added. One cluster dropped out after randomisation but before any inclusion of subjects. Primary outcome was selfrated health. Secondary outcomes were body weight, body mass index (BMI), work productivity, and health behaviours. Follow-up measurements were collected at 6 and 12 months. Effect sizes were determined in mixed effects models.

Results: At 12 months, the extensive intervention was not statistically different from the limited intervention for self-rated health (4.3\%; 95\%Cl -5.3-12.8), BMI (-0.81; 95\%Cl-1.87-0.26) and body weight $(-2.16$; 95\%Cl -5.49-1.17). The within-group analysis showed that in the extensive intervention group body weight $(-3.1 \mathrm{~kg} ; 95 \% \mathrm{Cl}-2.0$ to -4.3$)$ was statistically significantly reduced, whereas body weight remained stable in the limited intervention group $(+0.2 \mathrm{~kg} ; 95 \% \mathrm{Cl}$ -1.4 to 1.8). In both randomised groups productivity loss and physical activity increased and excessive alcohol use decreased significantly at 12 months.

Conclusions: There were no effects on self-rated health, body weight, and BMI. However, within the group with web-based tailored Health Risk Assessment including personalized advice body weight reduced significantly. Adding motivational coaching is promising to reduce body weight.
\end{abstract}

Trial registration: Retrospectively registered at the Netherlands Trial Registry with number NTR4894, at Nov 142014.

Keywords: Life style, Risk assessment, Cardiovascular diseases, Body weight, eHealth, Motivational interviewing

\footnotetext{
* Correspondence: t.kouwenhoven@erasmusmc.nl.

'Department of Epidemiology, Erasmus MC, University Medical Center

Rotterdam, Na2818, Postbus 2040, 3000, CA, Rotterdam, The Netherlands

2Department of Public Health, Erasmus MC, University Medical Center

Rotterdam, Rotterdam, The Netherlands

Full list of author information is available at the end of the article
}

(c) The Author(s). 2018 Open Access This article is distributed under the terms of the Creative Commons Attribution 4.0 International License (http://creativecommons.org/licenses/by/4.0/), which permits unrestricted use, distribution, and reproduction in any medium, provided you give appropriate credit to the original author(s) and the source, provide a link to the Creative Commons license, and indicate if changes were made. The Creative Commons Public Domain Dedication waiver (http://creativecommons.org/publicdomain/zero/1.0/) applies to the data made available in this article, unless otherwise stated. 


\section{Background}

Non-communicable diseases are a major burden all over the world. Health risk behaviours, such as smoking, unhealthy diet, and physical inactivity, are associated with obesity and cardiovascular diseases (CVD) [1], and are also responsible for substantial health care costs and indirect costs in the workplace $[2,3]$. In ageing societies, health promotion programmes that contribute to healthy ageing of the workforce are increasingly important $[4,5]$.

In western countries individuals are required to work longer due to increasing retirement ages. There is a societal need to work longer in good health. The workplace has been identified as a promising setting for health promotion, because of the possibility to reach large groups and the presence of a natural social network. Two approaches that have shown promise in improving unhealthy behaviours are a web-based Health Risk Assessment (HRA) and individual counselling by using Motivational Interviewing (MI). Some studies have demonstrated that a web-based HRA stimulated individuals to undertake health-promoting activities and achieved a healthier lifestyle, a decreased CVD risk, and reduced absenteeism in both work [6-8] and primary care settings [9]. Motivational interviewing as a coaching technique has shown beneficial effects on behavioral and biomedical outcomes in individuals with increased CVD risk [10-12], with maintenance of the effect at 12 months follow-up [13]. Web-based HRAs are appealing as they could reach large populations without extensive human interaction [9]. The major shortcoming of a purely web-based approach is low sustained participation [14]. A systematic review reported that maintenance of behavioral changes was higher in interventions with face-to-face contact than those without [15]. Addley et al. [16] recently suggested adding face-to-face contact in a health mentoring programme to an HRA to achieve enhanced benefits on health and work outcomes. Motivational interviewing is recommended as face-to-face communication strategy by The American Heart Association [17]. By nonjudgementally addressing a person's innate needs and values during different phases of change, MI-approaches contribute to sustainable change [18]. MI has potential benefits above tailored advice, but it requires intensive human and financial resources $[19,20]$. Although optimizing personalized prevention by blending a web-based HRA and face-to-face motivational counselling seems promising, little is known about whether adding these components to workplace health promotion programmes will increase their effectiveness.

The hypothesis for this study was that a web-based HRA combined with MI improves the motivation for behaviour change, and subsequently improves health behaviour and health more than a web-based HRA without MI. The main aim of the current study was to evaluate the effects of adding MI-coaching to a web-based HRA including tailored advice on health and work outcomes among employees with increased cardiovascular risk in the military workforce, the police organisation and an academic hospital.

\section{Methods \\ Study design}

The PerfectFit study was designed as a cluster-randomised controlled trial with randomisation carried out at organisational units within three large organisations with a workforce with physically and mentally demanding jobs: the military ( 9 clusters), the police force (3 clusters), and an academic hospital (5 clusters) [21]. The cluster design ensured that occupational health physicians (OP) delivering the intervention were only active within a single study arm. Reporting of the study was performed according to the CONSORT extension for cluster trials [22] (Additional file 1: Table S1 and S2).

Baseline measures were obtained from all participants between 2012 and 2014 after written informed consent was given. Web-based follow-up questionnaires were collected at 6 and 12 months. Anthropometric and blood measurements were repeated at 12 months. An extensive description of the study design and baseline characteristics is provided elsewhere [21]. The Medical Ethics Committee of Erasmus MC Rotterdam (METC) approved the study with number MEC-2012-459. The study was registered in the Netherlands Trial Registry with number NTR4894.

The academic hospital was included in the trial after trial commencement, for which approval of the METC was obtained. Reasons were the loss of one military cluster, leading to less inclusions than expected.

\section{Randomisation, blinding, and sample size calculation}

To guarantee allocation concealment, randomisation was performed by a researcher who was not otherwise involved in the trial, using $\mathrm{R}$ version 3.0.1.

A total of 18 clusters were randomised, and since 1 cluster dropped out prior to any inclusion of employees, analyses were performed on 17 clusters. Participants were included by 21 OPs. For the hospital, the first MI-session was performed by the OP and follow-up sessions by a lifestyle coach. Due to our design, OPs, lifestyle coaches and participants were not blinded.

The sample size calculation took into account the cluster design [23] with an estimated intracluster correlation coefficient of 0.05 . We estimated that approximately 220 participants per study arm were needed to demonstrate an effect size of $10 \%$ in self-rated health between the two groups [21]. 


\section{Participants}

A total of 652 employees of 40 years and over attended the 'cardioscreening' at occupational health centers, which consisted of a short web-based questionnaire, anthropometric measurements, and blood measurements, and is described in detail elsewhere [21]. Inclusion criteria were: 1 ) having angina or myocardial infarction in first degree relatives; 2) not meeting the Dutch physical activity norm of exercising five times a week at moderate intensity for at least half an hour; 3) smoking; 4) self-reported diabetes mellitus or random glucose $\geq 11.1 \mathrm{mmol} / \mathrm{l} ; 5)$ obesity (BMI $\geq 30 \mathrm{~kg} / \mathrm{m}^{2}$ and / or waist circumference $\geq 102 \mathrm{~cm}$ for men or BMI $\geq 30 \mathrm{~kg} / \mathrm{m}^{2}$ and/or $\geq 88 \mathrm{~cm}$ for women); 6) hypertension (diastolic value $>90 \mathrm{mmHg}$ or a systolic value $>140 \mathrm{mmHg}$ ) or the use of antihypertensive drugs); and 7) dyslipidaemia (total cholesterol $\geq 5 \mathrm{mmol} / \mathrm{l}$ or LDL cholesterol $\geq 2.5 \mathrm{mmol} / \mathrm{l}$ or triglycerides: $\geq 1.7 \mathrm{mmol} / \mathrm{l}$ or HDL cholesterol: $\leq 1.0 \mathrm{mmol} / \mathrm{l})$. Elevated risk for CVD was defined as having at least one of the inclusion criteria. Of the 652 screened individuals, 91.7\% $(n=598)$, had an elevated risk for CVD and were invited by the OP to participate in the study of which 491 (82.1\%] subjects provided informed consent.

\section{Interventions}

The limited (control) intervention programme consisted of the following elements:

a) A web-based HRA, including tailored and personalized feedback based on the participant's risk profile, with suggestions for particular health promotion activities, available within each organisation.

b) An electronic newsletter, providing information on the intervention (PerfectFit) and general information on a healthy lifestyle, which was sent to email-addresses using newsletter-software [24], every 2 to 3 months during the study period.

In the extensive intervention group, the intervention was extended with:

c) Seven individual coaching sessions (3 face-to-face and 4 by telephone) with an OP, together with more personalized suggestions for health promotion activities based on motivational elements in the HRA, and an additional motivational paragraph in the newsletters.

During the coaching sessions, the OP applied a client-centered counselling style with MI techniques such as asking open questions, reflecting, supporting, and raising ambivalence. Starting point of the counselling was problem feedback [25] by discussing the person's CVD risk profile and motivation to change health behaviour, which was integrated with important life goals and values. All OPs in the extensive intervention group received a basic training in MI of 3 full days and 3 follow-up coaching sessions of $4 \mathrm{~h}$.

\section{Outcome measures}

The primary outcome measure was self-rated health, assessed by the first question of the Short Form 36 Health Survey (SF-36) [26] ('Overall, how would you rate your health?') with 5 answers, ranging from 'very poor' to 'very good'. Answers were dichotomized in 'less than good' and 'good or very good' health, as was done in the power calculation [21].

The secondary outcome measures were body weight, BMI, work performance, and health behaviours. Body weight was expressed in kilograms and Body Mass Index (BMI) in $\mathrm{kg} / \mathrm{m}^{2}$. 'Obesity' was defined as BMI $\geq 30 \mathrm{~kg} / \mathrm{m}^{2}$. Body height and weight were measured at each OP's clinic at baseline and at 12 months with calibrated scales available at their occupational health clinics.

Work performance was estimated by work ability, sickness absence, and productivity loss at work. Work ability was measured with the first question of the Work Ability Index (WAI) questionnaire [27], rating a worker's current work ability relative to the best work ability during life on an 11-point scale ranging from 0 (unable to work) to 10 (current work ability equals best work ability ever). Sickness absence in days off work due to illness was determined by the 5th question of the WAI, and answers were categorized into no sickness absence (0 days), short-term (1-9 days), and long-term ( $\geq 10$ days). Productivity loss at work was assessed with the short version of the Work Limitations Questionnaire (WLQ-8) [28-30], consisting of four dimensions: physical (2 items), time management (2 items), mental-interpersonal ( 2 items), and output demands (2 item). Individuals rated impairments on a 5-point scale from 'always' to 'never, or 'does not apply to my job'. The WLQ-8 coding algorithm produced a summary score representing the percentage of productivity lost at work over the last 2 weeks due to health reasons.

Health behaviours addressed were physical activity (PA), fruit and vegetables, smoking, alcohol, and perceived stress. Compliance with the Dutch guideline on physical activity (PA) [31] was measured by asking 'are you at least 5 days a week, for at least 30 minutes per day, physically active at a moderate intensity (i.e. with a slightly increased heart rate and breathing rate, such as in vigorous walking or cycling)?' (yes/no). Compliance with the guidelines on a healthy diet [32] was assessed by self-reported daily intake of vegetables on a 6-point scale ('no vegetables' to ' 4 or more spoons of 50 grams each per day'), and fruits on a 7-point scale ('never' to 'twice a day'). The recommendation was not met if less 
than $200 \mathrm{~g}$ of vegetables and less than 2 pieces of fruit were consumed every day. Smoking was measured with the question 'do you smoke?' (yes/no). Alcohol intake was measured by asking the number of alcohol-units consumed per week with a 7 -point scale $(1=$ less than 1 glass per week', $7=$ ' 43 to 50 glasses per week'). The guideline was not met if more than 7 (women) or 14 (men) glasses per week were consumed [32]. The level of stress was measured by the INTERHEART-questionnaire [33]. We defined 'high stress level' as several periods or permanent stress at work or at home, severe financial stress, or 2 or more life events in the past year [33]. With the exception of healthy diet and high stress level, health behaviours were measured at 6 and 12 months by a short web-based questionnaire.

\section{Delivery of the intervention}

The quantity of the intervention delivered was expressed by number of face-to-face and telephone MI sessions, and the mean duration in minutes of MI counselling received. The fidelity of the intervention, i.e. the quality of MI, was determined by audio-records of a session every 3 months per OP [34]. Recorded sessions were transcribed verbatim and analysed using the validated Motivational Interviewing Treatment Integrity code (MITI) version 3.1.1 [35]. Coding was done by two experienced MI-coaches (TK, MW) who were also familiar with the scoring technique. Quality of MI was expressed by the MITI global score 'empathy' and the behaviour-count 'MI-adherence', since these may be predictive of successful client outcome [34]. 'Empathy' referred to the OP's efforts in understanding the client's perspective, ranging from 1 (low) to 5 (high). 'MI-adherence' referred to provision of information (teaching or feedback on personal information) in a MI-consistent way, and was calculated as percentage of MI-adherent remarks. MI quality was based on 35 recordings, ranging from 1 to 4 recordings per OP.

\section{Data analyses}

Differences between the limited and extensive intervention groups at baseline were evaluated with Chi-Square tests for dichotomous variables and ANOVA-tests for continuous variables. No adjustments for clustering were done because the intracluster correlation was low.

All analyses were performed according to the intention-to-treat principle, including all participants regardless of whether or not they received the intervention according to protocol. Non-response analyses were conducted to determine whether drop-out was associated with any baseline characteristics or with the type of intervention. Non-response was defined as no response to the questionnaire at 6 or 12 months. The changes in health, work outcomes and health behaviours within each group were evaluated at 6 and 12 months using paired T-tests for continuous variables and McNemar's test for categorical variables. No adjustments were done because the intracluster correlation was low.

A random intercept for organisation cluster was used to take into account the clustered design. The intercepts are allowed to vary between clusters. Furthermore, the intervention effect was adjusted for baseline health, work outcomes, and health behaviours, sex, age, and education, which were added as fixed effects. Missing values of adjustment variables were imputed using chained equations using the mice package in $R$. Since the percentage of missing values was low we used single imputation. The intra-cluster correlation was assessed to evaluate the within cluster variation, and was 0.08 at the highest, implying that the clustering had little effect on the results. Data were analysed using SPSS Statistics version 21. Imputation of missing baseline characteristics we used the mice package in R. Mixed effects models were fitted using the lme4 package.

\section{Results}

In Fig. 1 the flow of participants is shown with 9 clusters $(n=217)$ in the limited and 8 clusters $(n=274)$ in the extensive intervention group.

Our study population was 50.8 years on average, predominantly male with intermediate or high education (Table 1). Overall, 18.3\% considered themselves to be in less than good health, and health behaviours showed that $65.4 \%$ did not meet the Dutch physical activity guidelines and $86.6 \%$ did not meet the healthy diet guidelines. In total, $16.9 \%$ of the participants smoked, $11.8 \%$ used excessive alcohol, and $37.4 \%$ reported a high stress level. Since both randomised groups differed in age, sex, and educational level, all statistical analyses were fully adjusted for these factors. No adverse events of the intervention were reported.

The response was $72 \%$ at 6 months and $66 \%$ at 12 months. The extensive intervention approach contributed to retaining individuals in the study, and more MI sessions improved adherence (Additional file 2: Table S3). Response was higher among those with a higher workability (8 versus 7.5 ) and less productivity loss at work. There were no differences between OPs in both intervention groups in years affiliated with the organization (mean 11.9 , range 0.5 to 45.0 ) and working hours per week (mean 36.7, range 32.0 to 40.0). None of the OPs in the limited group had ever been MI-trained.

Table 2 shows the changes in health, work performance, and health behaviours during the study, and the effectiveness of the intervention. The proportion of subjects in 'less than good health' remained stable over time in the extensive group, but increased slightly in the limited group. After 12 months a statistically significant 


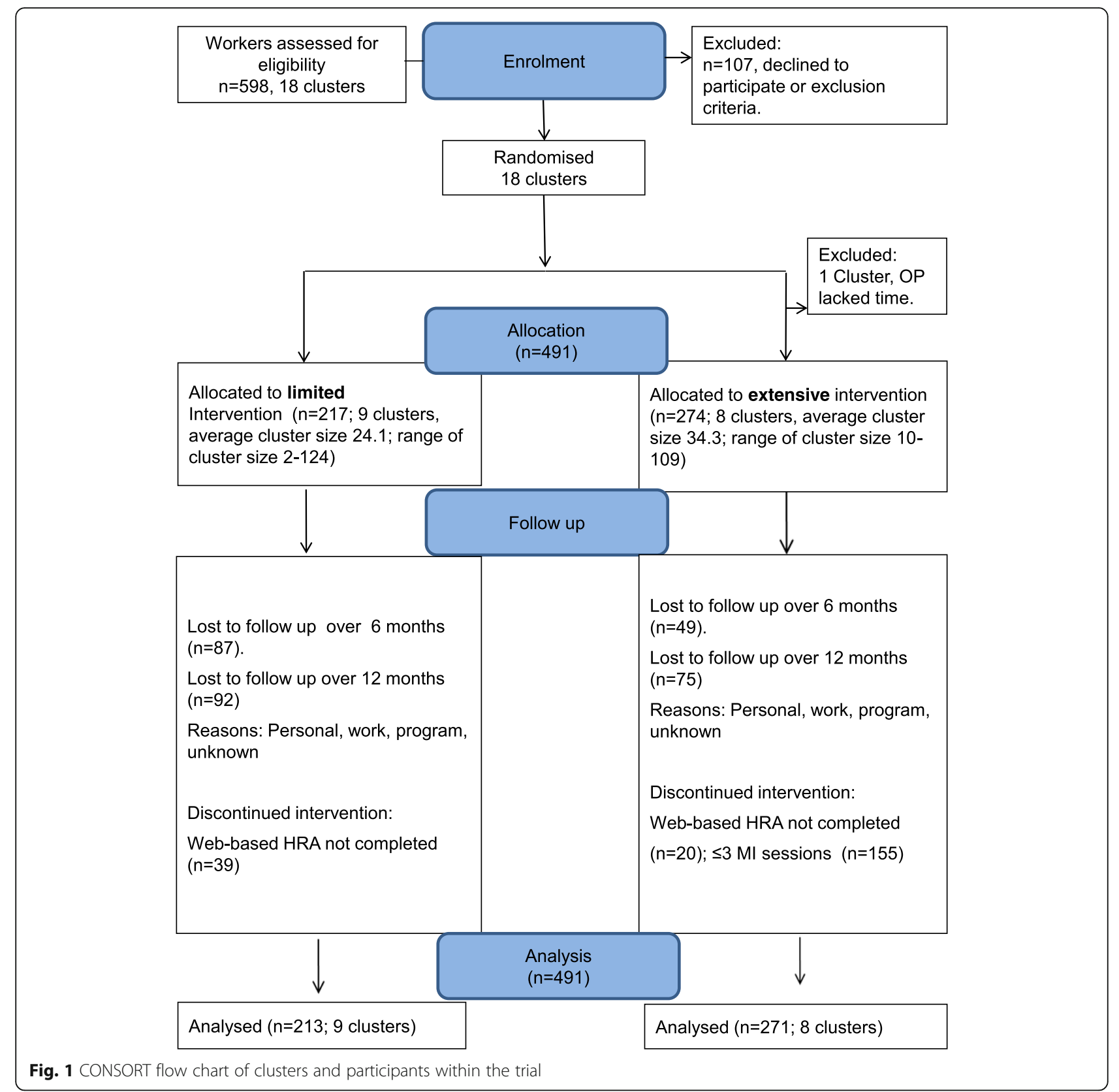

difference of 0.81 BMI points and $2.16 \mathrm{~kg}$ body weight was observed, favouring the extensive intervention. After adjustment for important individual characteristics the difference in BMI and body weight became insignificant, illustrating the imbalance in study populations in both programmes. Hence, a within-effect analyses was also conducted, showing that in the extensive intervention group there was a significant reduction of $0.69 \mathrm{~kg} / \mathrm{m}^{2}$ (3.1 kg body weight) in the extensive group, whereas no changes were found in the limited group. There were no significant differences in health behaviours between the groups. The proportion of individuals meeting the physical activity guidelines increased by more than $50 \%$ in both randomised groups. Alcohol consumption was equally reduced by $10 \%$ after 12 months in both randomised groups. In both randomised groups the prevalence of smoking reduced somewhat. A reduction of 1.6\% points in long-term sickness absence after 6 months and $7.2 \%$ points after 12 months was found in the extensive group, although not statistically significant.

The extensive group attended 4 MI-sessions on average (SD 2.41) with a total mean duration of $104 \mathrm{~min}$ (SD 64.8). The analysis on delivery of the intervention showed that, on average, the level of received MI was 3.5 for empathy (SD 0.54) and $83.7 \%$ was delivered at sufficient MI-adherence (SD 10.25). 
Table 1 Baseline characteristics of the study population $(n=491)$

\begin{tabular}{|c|c|c|c|c|}
\hline Characteristics & $\begin{array}{l}\text { Limited intervention } \\
n=217(44.2 \%)\end{array}$ & $\begin{array}{l}\text { Extensive intervention } \\
n=274(55.8 \%)\end{array}$ & $P$ value & $\begin{array}{l}\text { Missings } \\
n(\%)\end{array}$ \\
\hline \multicolumn{5}{|l|}{ Individual characteristics: } \\
\hline Age, years (mean, SD) & $51.62(6.0)$ & $50.19(5.6)$ & 0.003 & $1(0.2)$ \\
\hline Male $(n, \%):$ & $166(76.5)$ & $233(85.0)$ & 0.016 & 0 \\
\hline Level of education $(n, \%)$ : & & & 0.009 & $20(4.1)$ \\
\hline Low & $34(17.9)$ & $33(12.6)$ & & \\
\hline Medium & $116(61.1)$ & $140(53.6)$ & & \\
\hline High & $40(21.1)$ & $88(33.7)$ & & \\
\hline \multicolumn{5}{|l|}{ Health characteristics: } \\
\hline \multicolumn{5}{|l|}{ Self-rated general health: } \\
\hline Less than good & $32(17.2)$ & $58(22.3)$ & 0.185 & $45(9.2)$ \\
\hline BMI (kg/m2) (mean, SD) & $26.9(3.4$ & $27.5(3.6)$ & 0.066 & $15(3.1)$ \\
\hline \multicolumn{5}{|l|}{ Work characteristics: } \\
\hline Work ability (mean, SD) & $7.91(1.61)$ & $7.92(1.47)$ & 0.946 & $50(10.2)$ \\
\hline Sickness absence $(n, \%)$ & & & 0.894 & $53(10.8)$ \\
\hline 0 days & $92(50.3)$ & $123(48.2)$ & & \\
\hline $1-9$ days & $72(39.3)$ & $106(41.6)$ & & \\
\hline$\geq 10$ days & $19(10.4)$ & $26(10.2)$ & & \\
\hline Productivity loss at work $(\%, S D)$ & $2.93(3.46)$ & $2.97(3.62)$ & 0.916 & $103(21.0)$ \\
\hline \multicolumn{5}{|l|}{ Health risk behaviour ${ }^{a}, n(\%)$ : } \\
\hline Lack of physical activity & $133(72.7)$ & $188(72.3)$ & 0.932 & $48(9.8)$ \\
\hline Unhealthy diet ${ }^{\mathrm{b}}$ & $173(94.5)$ & $252(97.7)$ & 0.082 & $50(10.2)$ \\
\hline Smoking & $28(12.9)$ & $55(20.1)$ & 0.071 & 0 \\
\hline Excessive alcohol use $e^{c}$ & $26(15.9)$ & $32(14.0)$ & 0.617 & $99(20.2)$ \\
\hline High stress level $^{d}$ & 59 (32.2) & $106(41.1)$ & 0.059 & $50(10.2)$ \\
\hline
\end{tabular}

$B M I$ body mass index, $S D$ standard deviation

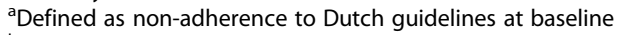

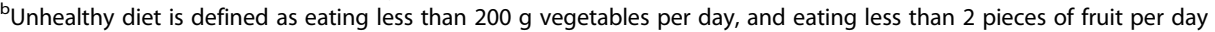

${ }^{\mathrm{C}}$ Meeting the alcohol guideline, which is not drinking more than 1 (women) or 2 (men) glasses of alcohol a day

${ }^{d}$ High stress level is defined as several periods or permanent stress at work or at home or severe financial stress or 2 or more life events (Ref. Lancet 2004 Rosengren)

\section{Discussion}

The results of this study show no effects on self-rated health, BMW, and body weight. The effects and sustainability of weight loss by adding MI-coaching to a web-based HRA among employees at increased CVD-risk in the military workforce, the police organisation and an academic hospital were promising, albeit not statistically significant. Both in the extensive and limited intervention group the proportion of subjects who engaged sufficiently in physical activity increased sharply, productivity loss increased, and excessive alcohol use declined.

The additional reduction of $0.81 \mathrm{~kg} / \mathrm{m}^{2}$ in BMI $(3.1 \mathrm{~kg}$ or $3.2 \%$ body weight loss) by the extensive intervention group compared to the limited group is high compared to other CVD-risk reducing interventions. Beishuizen et al. [36] showed in a meta-analysis of 47 studies a mean reduction in body weight of $1.3 \mathrm{~kg}$ in web-based interventions in individuals older than 50 years and at increased risk for
CVD. While MI was associated with a significant reduction in body weight of $1.5 \mathrm{~kg}$ in overweight and obese individuals [37], no effect of MI on BMI was found in a pooled analysis of 3 studies that included individuals at increased CVD risk [12]. Nevertheless, the effects on body weight found in our trial are even more pronounced than the $1.8 \mathrm{~kg}$ difference between intervention groups in Groeneveld's study [38], which was most similar to ours in terms of target population and intervention. Our study differed in that a web-based HRA with personalized and tailored feedback was provided and used as starting point for counselling instead of just a cardioscreening. The reduction in BMI could be due to targeting multiple health behaviours, which was found to be more effective than focussing on just one component [39]. Although it has been shown that effects are more pronounced in studies with shorter follow-up time [36], both Groeneveld et al. [38] and our study also showed reductions in BMI after 12 months. 
Table 2 Changes in health, work and health risk behaviour after 6 and 12-months follow-up in the limited and extensive intervention groups. The estimated effect is the difference between the extensive intervention vs. the limited intervention, adjusted for baseline characteristics. For example, the negative difference for BMI implies that the extensive intervention had a greater effect in reducing $\mathrm{BMI}$

\begin{tabular}{|c|c|c|c|c|c|c|}
\hline \multirow[b]{3}{*}{ Outcome: } & \multicolumn{4}{|c|}{ Effect follow-up minus baseline ${ }^{a}$} & \multicolumn{2}{|c|}{$\begin{array}{l}\text { Estimated effect }{ }^{b} \text { (difference) } \\
\text { between intervention groups } \\
(95 \% \mathrm{Cl})\end{array}$} \\
\hline & \multicolumn{2}{|l|}{ Limited intervention } & \multicolumn{2}{|c|}{ Extensive intervention } & \multirow[b]{2}{*}{6 months } & \multirow[b]{2}{*}{12 months } \\
\hline & 6 months & 12 months & 6 months & 12 months & & \\
\hline \multicolumn{7}{|l|}{ Health characteristics: } \\
\hline $\begin{array}{l}\text { General health (\%) } \\
\text { less than good }\end{array}$ & 3.1 & 4.1 & -1.8 & 0 & $2.6(-8.4 ; 9.2)$ & $4.3(-5.3 ; 12.8)$ \\
\hline $\begin{array}{l}\text { BMI }\left(\mathrm{kg} / \mathrm{m}^{\mathrm{b}}\right) \\
(\text { mean, } 95 \% \mathrm{Cl})\end{array}$ & na & $0.24(-0.20 ; 0.67)$ & na & $-0.69^{c}(-1.00 ;-0.39)$ & na & $-0.81(-1.87 ; 0.26)$ \\
\hline Bodyweight (kg) & na & $0.17(-1.44 ; 1.77)$ & na & $-3.12^{\mathrm{C}}(-4.26 ;-1.99)$ & na & $-2.16(-5.49 ; 1.17)$ \\
\hline \multicolumn{7}{|l|}{ Work characteristics: } \\
\hline $\begin{array}{l}\text { Work ability (0-10) } \\
\text { (mean, 95\%Cl) }\end{array}$ & $-1.89(-0.43 ; 0.05)$ & $-0.18(-0.45 ; 0.09)$ & $-0.02(-0.20 ; 0.16)$ & $-0.11(-0.35 ; 0.13)$ & $0.08(-0.19 ; 0.36)$ & $-0.01(-0.47 ; 0.46)$ \\
\hline \multicolumn{7}{|l|}{ Sickness absence (\%) } \\
\hline$\geq 10$ days & 2.4 & $10.9^{c}$ & -1.4 & -1.5 & $-1.6(-7.0 ; 5.2)$ & $-7.2(-15.5 ; 1.2)$ \\
\hline $\begin{array}{l}\text { Productivity loss } \\
(\%, 95 \mathrm{Cl})\end{array}$ & $1.84^{\mathrm{c}}(1.15 ; 2.53)$ & $2.31^{c}(1.56 ; 3.07)$ & $1.46^{\complement}(1.00 ; 1.93)$ & $1.47^{\mathrm{C}}(0.94 ; 2.00)$ & $-0.17(-1.07 ; 0.73)$ & $-0.44(-1.80 ; 0.92)$ \\
\hline \multicolumn{7}{|l|}{ Health risk behaviour: } \\
\hline $\begin{array}{l}\text { Lack of physical } \\
\text { activity (\%) }\end{array}$ & $-58.6^{c}$ & $-53.6^{c}$ & $-49.2^{c}$ & $-50.3^{c}$ & $-6.5(-14.6 ; 5.2)$ & $-5.6(-14.2 ; 5.0)$ \\
\hline Smoking (\%) & -4.6 & -3.2 & -2.3 & 0 & $10.5(2.4 ; 15.5)$ & $8.6(-0.1 ; 15.7)$ \\
\hline Excessive alcohol use (\%) & -5.2 & $-11.1^{c}$ & $-5.1^{c}$ & $-9.4^{c}$ & $2.0(-2.1 ; 6.9)$ & $0.0(-2.1 ; 6.9)$ \\
\hline
\end{tabular}

In contrast to the effects on BMI and body weight, the effects on productivity loss, smoking and physical activity in our study are harder to interpret. In contrast to previous studies reporting that risky behaviour was associated with increased productivity loss at work [40], our study showed an increased productivity loss at follow-up, while health behaviour improved. This increase of productivity loss may be related to major national reorganizations in both the police and the military during the study period, with consequent work-related stress leading to productivity loss [41]. Our results on smoking cessation following a workplace intervention are in line with other studies [42]. We observed a smaller effect in the extensive compared to the limited group, which is in contrast to abundant evidence by others $[43,44]$. Since previous research has shown that smoking is better targeted as the primary or only outcome instead of being integrated in a programme targeting multiple risk factors [42], this most likely explains our results. The sharp increase in the proportion of subjects meeting the Dutch guideline for physical activity cannot be attributed to the motivational interviewing, given that physical activity improved in both randomised groups. Nevertheless, the HRA result may have acted as a warning signal that subjects needed to improve rapidly in particular in the military and police where a good physical condition is a prerequisite for the job. This may also explain the strong decrease in excessive alcohol use in both intervention groups.

There are several possible reasons why the intervention showed a statistically significant effect on BMI compared to baseline in the extensive group but no statistically significant differences on other outcomes. Several issues may have reduced the beneficial effects of the extensive intervention, such as methodological issues, insufficient delivery of the intervention, or ineffectiveness for certain outcomes. The methodological limitation is linked to our cluster design with large cluster-size differences (ranging 1-124), which may have caused under-powering of the study. A linked issue is that a cluster RCT is sensitive to allocation bias, as was indeed present as illustrated by the disbalance in age, gender, and education at baseline between the extensive and limited intervention groups. Adjustment for these 
factors led to the lack of precision in the estimated effect of the extensive intervention group compared to the limited intervention group. Concerning the delivery of MI, both quantity and quality as provided by OPs need to be considered. Since the prescribed dose of 7 MI-sessions was not met by $75 \%$ of the individuals, whereas BMI decreased statistically significantly, this may suggest that the optimum MI-dose is lower than 7 or, alternatively, that this is determined by personal needs rather than one-size-fits-all. This is in line with the inconclusiveness in previous publications on the optimal dose restricted to individuals at risk or diagnosed with CVD [11], creating the need for future research focusing on what is the optimal dosage for whom. The quality of MI in this study appeared fairly low according to the MITI thresholds [35], with an insufficient level of MI-adherence and empathy at beginner's level. Since the awareness of the quality of MI as a factor in effectiveness of MI has grown [45], a more detailed exploration of MI-fidelity is needed $[34,45]$.

A potential limitation is that the intervention has failed to target individuals who needed it most, based on low work ability and high productivity loss at work. However, the average response rate of $77.8 \%$ in this study was high compared to $33 \%$ in other studies [46]. A second limitation is that this study lacked a third arm including a non-intervention-group. Although this means that changes in the intervention groups are not necessarily a result of the HRA, there is sufficient evidence that a purely web-based HRA impacts health and work at least in the short-term [6-9]. A third limitation is that the PerfectFit intervention might increase the participants' motivation to change, but not sufficiently to change their behaviour, resulting in an underestimation of the effect. This idea is strengthened by increased adherence to follow-up in the extensive group. A linked issue is that the three organisations may differ in organizational support for healthy behavior, but in the current study it was not possible to evaluate the influence of the organisation on participants' behavior. Individual health behaviour change is mediated by a multitude of factors [47], including a more job-specific approach [48] and involving multiple levels of the workplace such as management and colleagues [49], could improve the individual's work and health outcomes.

Strengths of our study are the performance in a real-life setting, the assessment of the additional effect of supplementing a web-based HRA with tailored advice and face-to-face coaching on both clinical and societal outcomes, and the assessment of sustainability by prolonged follow-up. Many interventions are effective in controlled research settings, but to achieve scaling-up such interventions they must be embedded within multiple sectors [50]. Since our study was performed in a real-life setting, in a multi-center approach in different sectors, and by the OPs who are working in these organisations, our findings may be generalisable to other organisations and applied in future implementation.

\section{Conclusions}

There were no effects on self-rated health, body weight, and BMI. However, within the group with web-based tailored Health Risk Assessment including personalized advice body weight reduced significantly. Adding personalized coaching to a web-based HRA in a 'blended care'-approach is promising in the reduction of BMI and body weight in employees at increased CVD risk. Future research may be aimed towards a) personalised prediction modelling to determine who will benefit optimally from a web-based HRA and who will need additional coaching, and b) the influence of a supportive work environment.

\section{Additional files}

Additional file 1: Table S1. CONSORT 2010 checklist for reporting a cluster randomised trial \& Extension of CONSORT for abstracts to reports of cluster randomised trials. Table S2. Extension of CONSORT for abstracts to reports of cluster randomised trials. (DOCX 33 kb)

Additional file 2: Table S3. Characteristics of non-responders at 6 or 12 months follow-up $(n=109)$. (DOCX $22 \mathrm{~kb}$ )

\section{Abbreviations}

BMI: Body Mass Index; CVD: Cardiovascular disease; HRA: Web-based health risk assessment; MI: Motivational interviewing; OP: Occupation Health Physician; PA: Physical Activity

\section{Acknowledgements}

We thank all participants of the study for their participation, and the participating OPs and OP-assistants for carrying out the study. Thanks to Erica Kroos and Jacqueline Mulder for listening and typing audio-recordings. Thanks to Machteld Wery for listening and coding audio-recordings.

\section{Funding}

Financial support was provided by ZonMW (grant number: 208030007). Additional funding was received from Erasmus Medical Center (grant number: 2013-13110)

\section{Availability of data and materials}

The datasets used and/or analyzed during the current study are available from the corresponding author on reasonable request.

\section{Authors' contributions}

TK contributed to the design, implementation, and data-collection and -analyses of the study and drafted the article. RK coordinated data-collection of the web-based HRA. TK and DN carried out statistical analyses. SR, AB, PH, RK and $\mathrm{MH}$ contributed to the conception and design of the study, provided critical revision of the article. MH was principal investigator. TK was project leader. All authors provided final approval of the version to be published.

\section{Ethics approval and consent to participate}

The study was approved by the Medical Ethics Committee of the Erasmus MC Rotterdam (METC) by registration number MEC 2012-459. Written informed consent was obtained from all participants, after they were found eligible at the cardioscreening, and after they were informed on all aspects of the study by OP. The study was registered in the Netherlands Trial Registry with number NTR4894. 


\section{Competing interests}

The authors declared the following potential conflicts of interest with respect to the research, authorship, and/or publication of this article: RK is director and co-owner of NIPED. This institute developed the web-based HRA used in this programme. MH receives royalties from Cambridge University Press for a textbook she authored on Medical Decision Making.

\section{Publisher's Note}

Springer Nature remains neutral with regard to jurisdictional claims in published maps and institutional affiliations.

\section{Author details}

'Department of Epidemiology, Erasmus MC, University Medical Center Rotterdam, Na2818, Postbus 2040, 3000, CA, Rotterdam, The Netherlands. ${ }^{2}$ Department of Public Health, Erasmus MC, University Medical Center Rotterdam, Rotterdam, The Netherlands. ${ }^{3}$ Department of Occupational Health, Erasmus MC, University Medical Center Rotterdam, Rotterdam, The Netherlands. ${ }^{4}$ NDDO Institute for Prevention and E-health Development (NIPED), Amsterdam, The Netherlands. ${ }^{5}$ Staff Joint Health Care Division, Command Service Center, Ministry of Defense, Utrecht, The Netherlands. ${ }^{6}$ Department of Radiology, Erasmus MC, University Medical Center Rotterdam, Rotterdam, The Netherlands. ${ }^{7}$ Center for Health Decision Sciences, Harvard T.H. Chan School of Public Health, Harvard University, Boston, USA

\section{Received: 10 November 2017 Accepted: 29 May 2018} Published online: 19 June 2018

\section{References}

1. World Health Organisation (WHO). Global status report on noncommunicable diseases, vol. World Health Organisation (WHO); 2014. ISBN: 9789241564854 www.who.int.

2. Goetzel RZ, Pei X, Tabrizi MJ, Henke RM, Kowlessar N, Nelson CF, et al. Ten modifiable health risk factors are linked to more than one-fifth of employeremployee health care spending. Health Aff. 2012;31(11):2474-84.

3. Dee A, Kearns K, O'Neill C, Sharp L, Staines A, O'Dwyer V, et al. The direct and indirect costs of both overweight and obesity: a systematic review. BMC Res Notes. 2014;7(1):242

4. World Health Organization (WHO). World report on ageing and health. World Health Organisation (WHO); 2015. ISBN 978924156504 2. www.who.int.

5. Fuster V. Global burden of cardiovascular disease. Time to implement feasible strategies and to monitor results. J Am Coll Cardiol. 2014;64(5):520-2.

6. Colkesen EB, Niessen MA, Peek N, Vosbergen S, Kraaijenhagen RA, van Kalken CK, et al. Initiation of health-behaviour change among employees participating in a web-based health risk assessment with tailored feedback. J Occup Med Toxicol. 2011;6(1):5.

7. Soler RE, Leeks KD, Razi S, Hopkins DP, Griffith M, Aten A, et al. A systematic review of selected interventions for worksite health promotion: the assessment of health risks with feedback. Am J Prev Med. 2010;38(2, Supplement):S237-S62.

8. Niessen MAJ, Kraaijenhagen RA, Dijkgraaf MGW, Van Pelt D, Van Kalken CK, Peek N. Impact of a web-based worksite health promotion program on absenteeism. J Occup Environ Med. 2012;54(4):404-8.

9. vd B-DK, Rengers AH, Niessen MA, de WNJ, Kraaijenhagen RA. Personalized prevention approach with use of a web-based cardiovascular risk assessment with tailored lifestyle follow-up in primary care practice - a pilot study. Eur J Prev Cardiol. 2015;23(5):544-51.

10. Lundahl B, Moleni T, Burke BL, Butters R, Tollefson D, Butler C, et al. Motivational interviewing in medical care settings: a systematic review and meta-analysis of randomized controlled trials. Patient Educ Couns. 2013:93(2):157-68.

11. Lin JS, O'Connor EA, Evans CV, Senger CA, Rowland MG, Groom HC. Behavioral Counseling to Promote a Healthy Lifestyle for Cardiovascular Disease Prevention in Persons With Cardiovascular Risk Factors An Updated Systematic Evidence Review for the U.S. Preventive Services Task Force. Evidence Report No 113 AHRQ Publication No 13-05179-EF-1. Rockville, MD: Agency for Healthcare Research and Quality; 2014

12. Lee WWM, Choi KC, Yum RWY, Yu DSF, Chair SY. Effectiveness of motivational interviewing on lifestyle modification and health outcomes of clients at risk or diagnosed with cardiovascular diseases: a systematic review. Int J Nurs Stud. 2016;53:331-41.

13. Hardcastle SJ, Taylor AH, Bailey MP, Harley RA, Hagger MS. Effectiveness of a motivational interviewing intervention on weight loss, physical activity and cardiovascular disease risk factors: a randomised controlled trial with a 12month post-intervention follow-up. Int J Behav Nutr Phys Act. 2013;10(1):40

14. Krebs P, Prochaska JO, Rossi JS. A meta-analysis of computer-tailored interventions for health behavior change. Prev Med. 2010;51(3-4):214-21.

15. Brianna F, Neuhaus M, Winkler E, Eakin E. Systematic review of maintenance of behavior change following physical activity and dietary interventions. Health Psychol. 2011;30(1):99-109.

16. Addley K, Boyd S, Kerr R, McQuillan P, Houdmont J, McCrory M. The impact of two workplace-based health risk appraisal interventions on employee lifestyle parameters, mental health and work ability: results of a randomized controlled trial. Health Educ Res. 2014;29(2):247-58.

17. Artinian NT, Fletcher GF, Mozaffarian D, Kris-Etherton P, Van Horn L, Lichtenstein $\mathrm{AH}$, et al. Interventions to promote physical activity and dietary lifestyle changes for cardiovascular risk factor reduction in adults: a scientific statement from the American Heart Association. Circulation. 2010;122(4):406-41.

18. Rollnick S, Miller WR, Butler CC. Motivational interviewing in health care. Helping patients change behavior. New York: The Guilford Press; 2008.

19. Simpson SA, McNamara R, Shaw C, Kelson M, Moriarty Y, Randell E, et al. A feasibility randomised controlled trial of a motivational interviewing-based intervention for weight loss maintenance in adults. Health Technol Assess. 2015;19(50).

20. Op den Akker H, Cabrita M, Op den Akker R, Jones VM, Hermens HJ. Tailored motivational message generation: a model and practical framework for real-time physical activity coaching. J Biomed Inform. 2015;55:104-15.

21. Kouwenhoven-Pasmooij TA, Djikanovic B, Robroek SJW, Helmhout P, Burdorf A, Hunink MGM. Design and baseline characteristics of the PerfectFit study: a multicenter cluster-randomized trial of a lifestyle intervention in employees with increased cardiovascular risk. BMC Public Health. 2015;15(1):715.

22. Campbell MK, Piaggio G, Elbourne DR, Altman DG. Consort 2010 statement: extension to cluster randomised trials. BMJ [Br. Med. J.]. 2012;345:e5661.

23. Eldridge S, Kerry S. A practical guide to cluster randomized trials in health services research. London, UK: John Wiley \& Sons; 2012.

24. The Rocket Science Group: MailChimp. Available from: https://mailchimp. com/. Accessed 2012-2015.

25. Lundahl B, Burke BL. The effectiveness and applicability of motivational interviewing: a practice-friendly review of four meta-analyses. J Clin Psychol. 2009;65(11):1232-45

26. McHorney CA, Ware JE, Raczek AE. The MOS 36-item short-form health survey (SF-36): II. Psychometric and clinical tests of validity in measuring physical and mental health constructs. Med Care. 1993;31(3):247-63.

27. IIImarinen J. The work ability index (WAI). Occup Med. 2007;57(2):160.

28. Lerner D, Amick B, Rogers WH, Malspeis SS, Bungay K, Cynn D. The work limitations questionnaire. Med Care. 2001;39(1):72-85.

29. Burton WN, Chen C-Y, Conti DJ, Pransky G, Edington DW. Caregiving for ill dependents and its association with employee health risks and productivity. J Occup Environ Med. 2004:46(10):1048-56.

30. Lerner D, Amick B, GlaxoWellcome I. Work Limitations Questionnaire, C 1998, The health institute, Tufts Medical Center f/k/a new England Medical Center hospitals, Inc; 1998, updated 2013. Boston.

31. Kemper HCG, Ooijendijk WTM, Stiggelbout M. Consensus over de Nederlandse norm voor gezond bewegen. Tijdschrift voor gezondheidswetenschappen. 2000;3(78):180-3

32. Gezondheidsraad. Richtlijnen goede voeding 2015. Den Haag: Gezondheidsraad; 2015.

33. Rosengren A, Hawken S, Ônpuu S, Sliwa K, Zubaid M, Almahmeed WA, et al. Association of psychosocial risk factors with risk of acute myocardial infarction in 11119 cases and 13648 controls from 52 countries (the INTERHEART study): case-control study. Lancet. 364(9438):953-62.

34. Jelsma JGM, Mertens V-C, Forsberg L, Forsberg L. How to measure motivational interviewing Fidelity in randomized controlled trials: practical recommendations. Contemp Clin Trials. 2015:43:93-9.

35. Moyers TB, Martin T, Manuel JK, Miller WR, Ernst D. Revised Global Scales: Motivational Interviewing Treatment Integrity 3.1.1 (MITI 3.1.1). University of New Mexico: Center on Alcoholism, Substance Abuse and Addictions (CASAA); 2010.

36. Beishuizen CRL, Stephan BCM, van Gool WA, Brayne C, Peters RJG, Andrieu $S$, et al. Web-based interventions targeting cardiovascular risk factors in middle-aged and older people: a systematic review and meta-analysis. J Med Internet Res. 2016;18(3):e55.

37. Armstrong MJ, Mottershead TA, Ronksley PE, Sigal RJ, Campbell TS, Hemmelgarn BR. Motivational interviewing to improve weight loss in overweight and/or 
obese patients: a systematic review and meta-analysis of randomized controlled trials. Obes Rev. 2011;12(9):709-23.

38. Groeneveld IF, Proper KI, van der Beek AJ, van Mechelen W. Sustained body weight reduction by an individual-based lifestyle intervention for workers in the construction industry at risk for cardiovascular disease: results of a randomized controlled trial. Prev Med. 2010;51(3-4):240-6.

39. King K, Meader N, Wright K, Graham H, Power C, Petticrew M, et al. Characteristics of interventions targeting multiple lifestyle risk Behaviours in adult populations: a systematic scoping review. PLoS One. 2015;10(1):e0117015.

40. Katz AS, Pronk NP, Lowry M. The association between optimal lifestylerelated health behaviors and employee productivity. J Occup Environ Med. 2014;56(7):708-13.

41. Yang T, Zhu M, Xie X. The determinants of presenteeism: a comprehensive investigation of stress-related factors at work, health, and individual factors among the aging workforce. J Occup Health. 2016;58(1):25-35.

42. Cahill K, Lancaster T. Workplace interventions for smoking cessation (Review). Cochrane database of systematic reviews. 2014;(2):CD003440

43. Keyserling TC, Sheridan SL, Draeger LB, et al. A comparison of live counseling with a web-based lifestyle and medication intervention to reduce coronary heart disease risk. A randomized clinical trial. JAMA Intern Med. 2014;174(7): 1144-57.

44. Lai DT, Cahill K, Qin Y, Tang JL. Motivational interviewing for smoking cessation. Cochrane Database Syst Rev 2010;1.

45. Madson MB, Schumacher JA, Baer JS, Martino S. Motivational interviewing for substance use: mapping out the next generation of research. J Subst Abus Treat. 2016:65:1-5.

46. Robroek SJW, van Lenthe FJ, van Empelen P, Burdorf A. Determinants of participation in worksite health promotion programmes: a systematic review. Int J Behav Nutr Phys Act. 2009;6:26.

47. Hammer SS, Liebherr M, Kersten S, Haas CT. Adherence to worksite health interventions: practical recommendations based on a theoretical framework. Journal of Workplace Behavioral Health. 2015;30(4):325-43.

48. Plat MJ, Frings-Dresen MHW, Sluiter JK. A systematic review of job-specific workers' health surveillance activities for fire-fighting, ambulance, police and military personnel. Int Arch Occup Environ Health. 2011;84(8):839-57.

49. Hendriksen I, Snoijer M, de Kok B, van Vilsteren J, Hofstetter H. Effectiveness of a multilevel workplace health promotion program on vitality, health, and work-related outcomes. J Occup Environ Med. 2016;58(6):575-83.

50. Reis RS, Salvo D, Ogilvie D, Lambert EV, Goenka S, Brownson RC. Scaling up physical activity interventions worldwide: stepping up to larger and smarter approaches to get people moving. Lancet. 388(10051):1337-48.

\section{Ready to submit your research? Choose BMC and benefit from}

- fast, convenient online submission

- thorough peer review by experienced researchers in your field

- rapid publication on acceptance

- support for research data, including large and complex data types

- gold Open Access which fosters wider collaboration and increased citations - maximum visibility for your research: over $100 \mathrm{M}$ website views per year

At BMC, research is always in progress.

Learn more biomedcentral.com/submissions 